\title{
Plant Ethics or an Environment for the Birth of a New Human? An Exploration in Radical Ethics for Sustainable Architecture
}

\author{
ANDREA SUSAN WHEELER
}

lowa State University

\begin{abstract}
Theorists of sustainable design frequently argue for the need to perceive the world differently, to find new ways to live, and to create new values to replace old. Ethical questions are implicit in such explorations and pitted against exploitative relationships to the environment and other living beings. An ecological ethic may be argued as inclusive in its concern for preserving the inter-relationship of all organisms to their environments but contemporary environmental philosophy and can have an ambiguous relationship to social ethics. To address such dilemmas, architecture must open its horizon to new and radical ways of thinking and being. Architecture needs new ethical philosophy. In this paper, I explore some radical thinkers of environmental and social ethics, and their critics, and suggest the beginning of an implication for approaches to sustainable architecture.
\end{abstract}

This paper is supported by a research grant from lowa State University, Center for Excellence in the Arts and Humanities.

\section{SUSTAINABLE DESIGN}

That we need to perceive the world differently is not an uncommon statement within the field of sustainable design. Our habits of living, exploitative desires and expectations, and excessive resource consumption, have irrevocably altered planetary conditions. As Bill McKibben writes: 'We simply can't live on the earth as if it was the old earth - we've foreclosed that option'. It is no longer a matter of modifying existing design methods and building techniques with the aim of reducing consumption but of finding new ways to live, new values that can substitute for old, new ways of being that do not continue to reproduce exploitative relationships. Such arguments have been seen as a reaction against a "technocist supremacy" and Guy and Farmer, for example, identify a number of different competing logics that they suggest describe the field of sustainable design, with the aim to dislodge this dominant technical approach. Logic, in this argument, they define as 'a specific ensemble of ideas, concepts and categorizations that are produced, reproduced and transformed in a particular set of practices through which meaning is given to social and physical realities'. These logics however, are not meant to be exclusive, or frozen in time or space (or even stable) but rather merging, colliding, co-inhabiting a debate where the actors all have very different perspectives on the problem to be addressed. Their categorizations are a crude as they admit; nevertheless, they demonstrate how an architectural commitment to sustainable design can differ greatly in '...interpretation of the causes of, and hence the solution to, unsustainability'. The important point they make is that the 'environmental problematique' is rarely ever discussed with recognition of the full complexity it demands. While architects are both practicing sustainable architecture, and theorizing about it, there is no proper agreement in the way the challenge of sustainability is either framed, the way questions are formulated and refined, nor how solutions are imagined: Aspiration can be widely felt, but poorly defined. As Guy argues, competing environmental debates are the result of contradictory certainties: '...divergent and mutually irreconcilable sets of convictions both about the environmental problems we face and the solutions that are available to us'. But if we have a multiplicity of approaches and each 'logic' has its associated convictions, can an ethics of sustainable design even be discussed? Moreover, the radical edges of sustainable design are not easy to fit into such categories characterizing sustainable architecture, and are easily dismissed. In this paper, I introduce two such edges broadly described as plant ethics and a feminist approach to human development ethics, to examine the question of ethics in sustainable architecture.

\section{COMPETING LOGICS OF SUSTAINABLE DESIGN}

Guy and Farmer's six logics include: eco-technical, eco-aesthetic, eco-medical, eco-centric, eco-social and eco-culture logics. While some architects may identify their approaches within this framework, intentions can be complex and concerns do not always easily fit within only one category; encompassing more than one, or indeed all, of these categories. There are many scholars who want to move the problem of sustainable development out of the dominant technical agenda citing a wide range of environmental philosophies and adopting many different methodological approaches. For example, the lack of priority given to the social is John Ehrenfeld's concern. He criticizes the prevalence of an environmental concern over a primary social ethic. He writes:

Sustainability has been seen primarily as an environmental problem and only secondly as a social problem. I believe that this is backward. Sustainability is first a human problem and then an environmental problem. If we fail to address the unsustainability of the modern human being, we will not be able to come to grips with other aspects of sustainability.

His attention is directed to how we understand ourselves as human beings and his criticism is not simply about how, as 


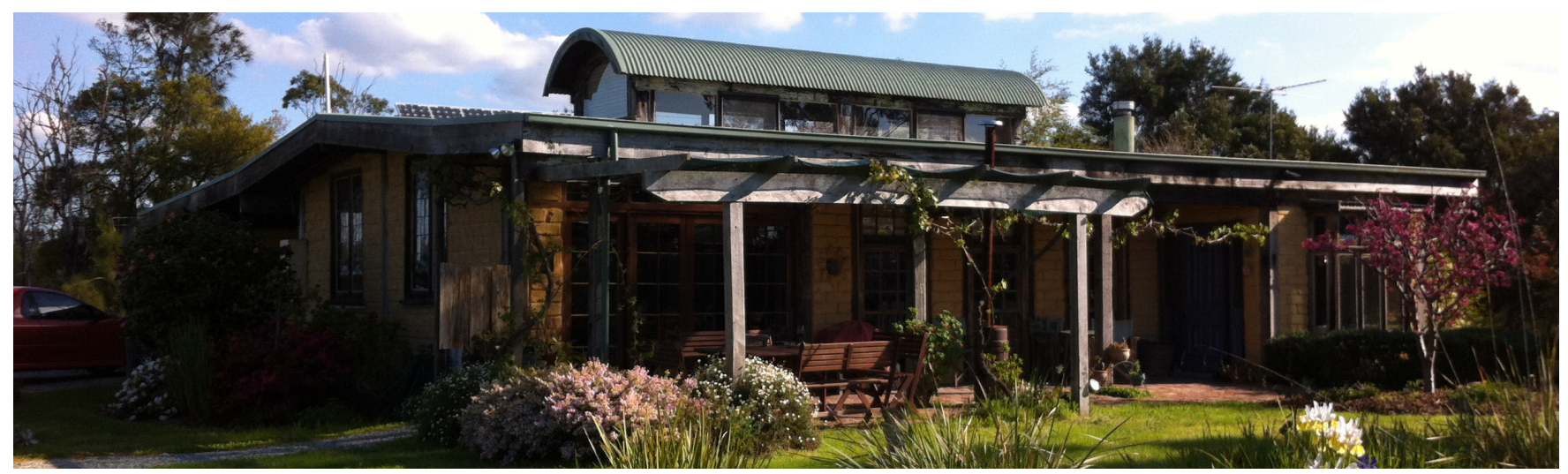

Figure 1: The Elizabeth Hartnell-Young House, Melbourne Australia (self build project using recycled building materials, off-grid).

humanity, we can survive the environmental crises we face, but how we can live freely and fully within our ecological limits. Sustainability, he argues, as a definition of terms is the possibility that humans and other life will flourish on the earth together forever. David Orr has equally argued for the reconstitution of how we live, writing in terms of aesthetics, education and well-being. His work has included, in particular, early proposals for greater ecological literacy and thus promotes a strong educational agenda. Stuart Walker, a theorist and practitioner, also argues that we need to go beyond the simple assumption of growth and to consider more meaningful notions of human progress. Walker proposes that design must be attentive to spirituality, and this is not an infrequent suggestion amongst other sustainability theorists. This question is raised by those looking to deeply challenge the consumerist agenda in contemporary culture. Walker describes his spirituality as a drive for personal meaning lost to the modern world, an attitude that could act in moderating consumerism and thus with environmental ramifications. Walker argues to add spirituality to the triple bottom line of economic, ethical and environmental accountability. In addition, Tim Jackson's approach, economic development as prosperity without growth, ${ }^{15}$ refines prosperity as the capabilities that people have to flourish as human beings, and within the ecological and resource constraints of a finite planet. ${ }^{16}$ This redefinition of growth is, however, he admits, a challenge that is both philosophical and pragmatic in nature, demanding understanding of the social and psychological conditions of living well.

Reformulating social ethics, and developing theories of wellbeing capable of reflecting on new environmental circumstances; such provocations towards change, to imagining a better world: economically viable, culturally vibrant, deeply satisfying and committed to sustainable lifestyles, are nevertheless, complex questions that span the full range of social, environmental, economic and spiritual. If there could be a sliding scale - a ladder of sustainability even, not only as Susan Baker has described for sustainable development ${ }^{18}$
- ranging from weak to strong, from anthropocentric to eco-centric - but also in architecture. Even this conceptualization raises questions: is an approach to rethink what it means to be human thriving in environment with other living beings, strong? Is the technical approach weak? Or should we devise a scale of concern with social ethics on one side and environmental ethics on the other? Baker argues: 'The varieties of approaches to sustainable development are an indication of differing beliefs about the natural world held in different societies, cultures and historical settings and at the individual level.' The problem, however, is that sustainable development itself, is, by history, by definition (especially if that definition is derived from the Bruntland Report) first and foremost a matter of human well-being, a view Baker describes as anthropocentric or human-centric.

\section{TECHNOCIST SUPREMACY}

The ladder of sustainability is a tool demonstrating Baker's ideological position, whereas Guy and Farmer's categories quite deliberately contain no such hierarchies of weak and strong. Their purpose is to illustrate, as they state, the discursive, mobile and ever-changing nature of the field. To call to attention the limits of science and technology, and recognize that there are aspects of our humanness that design cannot address, or that lie beyond the empirical framework of naturalistic materialism, this is, nevertheless, a project set against modernity. On the 'weak' bottom rungs of Baker's ladder are interventions that maintain our existing systems of value strongly in place, interventions offering technical solutions to a society whose desires and expectations can be anticipated to continue to remain the same. At the top of her ladder, are strong solutions, visions aimed at structural change to society, the economy and to political systems. Of those on this strong side, Baker writes that some reject the idea of sustainable development as formulated by Bruntland, but some have also gone on to modify the Bruntland definition, injecting it with radical, socialist considerations. ${ }^{22}$ Fifty years ago, before 'sustainable development' existed, there were forerunners of an environmental debate in architecture, criticizing excessive use of energy and resources, and overdependence on mechanical systems. These were thinkers and architects who wanted to build radically new futures, to 
design radically new social and environmental worlds changed by new technologies and new ways of living. But despite such modification and visionary innovation, the technologically driven approaches to the problem of sustainable development with their socially conservative agendas still dominate. At this end of the spectrum, lies the very recent book of 2017 entitled: Drawdown, the most comprehensive plan ever proposed to reverse global warming. The perspective of the author is an invitation to build, innovate and effect change, as '...a pathway that awakens creativity, compassion, and genius.' Hawken's argument is a call for new creative ideas, better ideas, new solutions and fixes. ${ }^{24}$ The ideas (both technical and social), all with the potential to reverse global warming - the most effective topping the list, those with lessening potential lower down in the list - are exercises in optimism. Hawken's prioritization for effective design solutions (a list of effective solutions determined by sophisticated performance modelling) are with lessening effectiveness: refrigeration management; wind turbines (onshore); reduced food waste; plant-rich diet; tropical forests; educating girls; family planning; solar farms; silvopasture (cattle grazing in forests); rooftop solar. Like buildings modelled for energy success, such evaluation nevertheless depends on the complexity of the modelling tool to effectively and accurately emulate the real.

\section{SOCIAL ETHICS IN ARCHITECTURE}

Every research method and every design approach contains philoEvery research method and every design approach contains philosophical assumptions, worldviews, epistemologies, ontologies, paradigms and beliefs, in its processes and procedures. The value of alternative or radical social approaches to sustainability are that in they have put at the heart of the issue what it means to be human and draw attention to the limits of such scientific inquiries. Buildings shape us, they gather us into relationship, and influence what we can become. Our relationship to our environment, is who we are. This is a very different way of looking at the environment, to that which is implicit in the technical logic of accounting methods so common in sustainable design. As a way of understanding our reality they constrict and reduce '....we manipulate and demand from our world rather than meet it in an attitude of sparing and preserving -- i.e., allowing it to be and become. ${ }^{25}$ While Hawkens' interventions are in a human world where our 'climate' no longer gives us our sense of security, and where this realization disturbs us profoundly at the level of our feelings. Climate, some authors argue is understood better through the humanities Climate Mike Hulme argues is the ordinary man's expectation of weather. ${ }^{26} \mathrm{He}$ states: 'I believe we need a richer understanding of the idea of climate itself. My argument is that climate-as it is imagined and acted upon - needs to be understood, first and foremost, culturally and that the environmental humanities can enrich and deepen such an understanding.'

Another critic of sustainable development, John Ehrenfeld states that we need to be aware not of the environmental

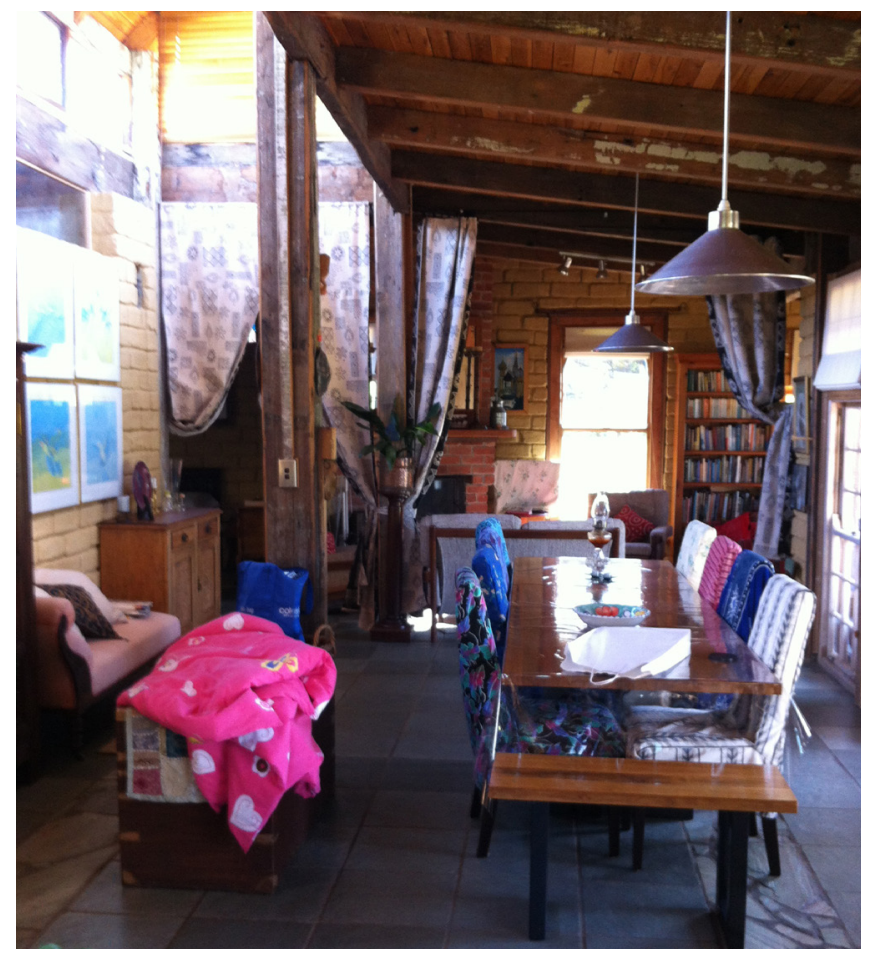

Figure 2 The Elizabeth Hartnall-Young House, Melboure, Australia, interior.

but the social, over and above the environmental, in order to address the demands of sustainable development. For Ehrenfeld the approach to sustainability this calls for, is not a social fix nor a behavioral change, but a change the way we think, in the way we organize society: It demands a reexamination of who we are, and why we are here, and how we are connected to everything around us. The old way of thinking no longer works, he argues, and it will not be able to solve the problems it has created. His goal is not thereby all about needs or even frugality, but about what it is to grow and live to the fullest. ${ }^{28}$ These arguments borrow from the traditions of eco-philosophy and phenomenology, and Guy and Farmer would call this an eco-cultural argument, but clearly set against the technocist agenda. Ehrenfeld argument is a little more defined too, he writes: 'To be truly authentic, to realize the potential of flourishing, we need a shift from a view of ourselves first from one of Having to one of Being, and second from one of Needing to one of Caring. ${ }^{29}$ Ehrenfeld emphasizes a fundamental reorientation of values that engage with both environmental and cultural concerns. He proposes the development of a 'different story' to replace the dominant one of what it means to be human (by which he means set against Nature or in dominion over Nature), and he borrows not only from phenomenology but also from sociologists and Critical Theory. He writes that sustainable development '... involves breaking addictions that have been put in place by the existing modern culture and replacing them with an adjusted and amended set of values, beliefs, and behaviors, one that fulfills the broken promises that have left people unsatisfied.' Social ecologists according to Guy and Farmer 


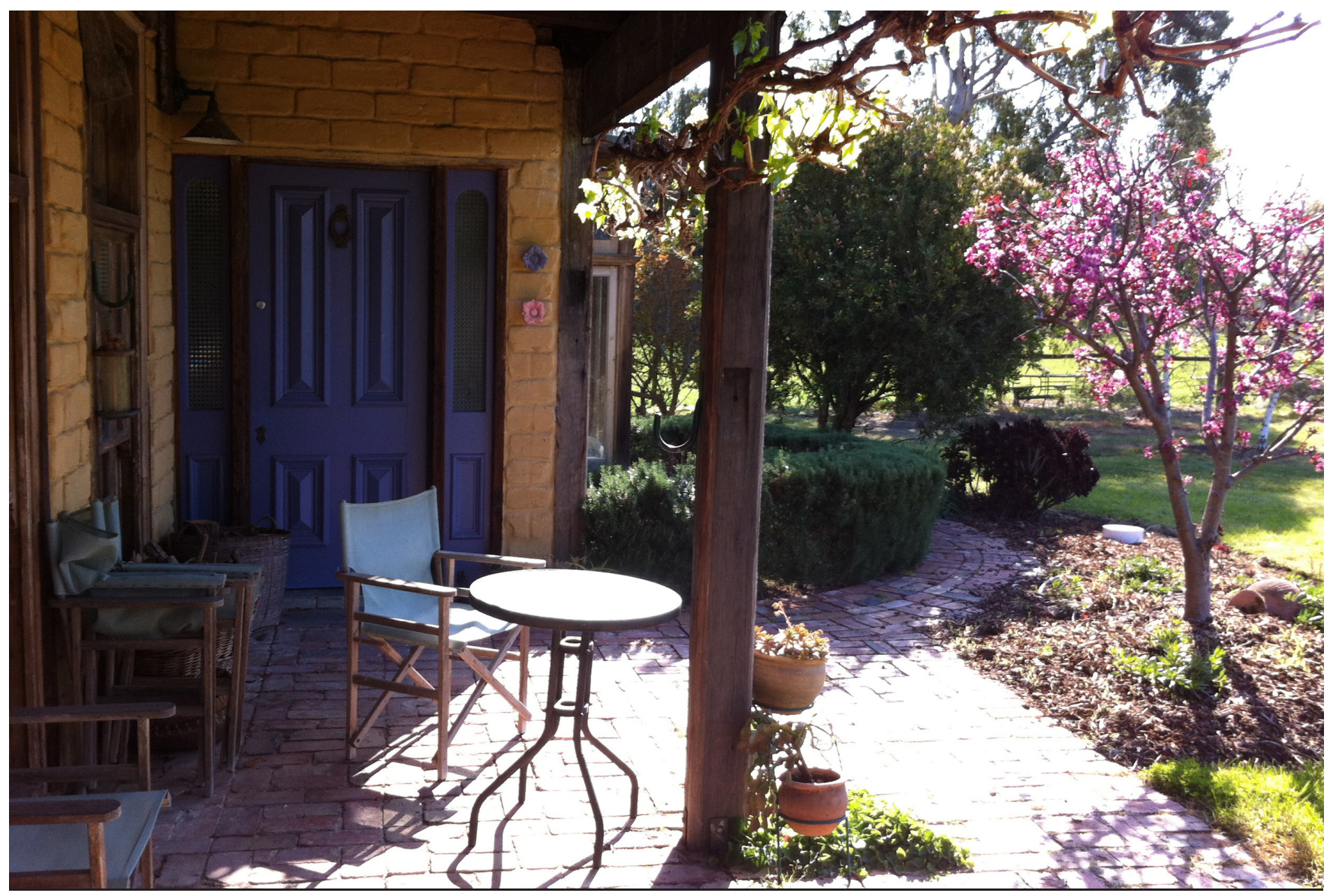

Figure 3 The Elizabeth Hartnall-Young House, Exterior Living Space.

'...believe that human domination and degradation of nature arises out of social patterns of domination and hierarchy, patterns of social life in which some human exercise control or domination over others.' Environmental and ecological destruction is therefore best understood as form of human domination, and the more hierarchal and oppressive the nature of society, the more likely that it will abusive and dominate the environment. Such questions about how we understand the environment in which we live are strongly reinforced and reflected by contemporary sociologists who also argue that positivism is in crisis. Nigel Fielding writes: ' $[\mathrm{w}]$ here grand challenges touch on what humans think, feel and do, our craving for experiential data, for people's stories' can only be met by qualitative exploration'. Beck and Sznaider also call for a move away from normative approaches that ignore the apparent banal forms of everyday life to 'bring sociology back to its subject matter - reality.' If reality is the subject matter of environmental inquiry then, for architecture, and our scientific architectural methods of inquiry are in crisis, innovative methodology may be a solution. Sarah Pink et al., for example, have created innovative ethnographic methodologies to collect social data aimed at including the forgotten voices of building users even including construction workers. ${ }^{34}$ However, if it is a deeper theoretical investigation into the ethics of the built environment we seek, and a call to consider who we are as human beings in relation to our environments, we still need to be able to open the cultural horizon of the discipline and to find new directions learning from more radical thinkers not so easily categorized by theorists of architecture. The radical edges of theory are moreover, not easy to identify, but the contest between environmental and a poorly considered social ethic is nevertheless, recognizable.

\section{PLANT ETHICS}

If the environment in architecture is a contested terrain and the problem raised, reality. The phenomenological tradition plays an influential role in this contest terrain. How man finds meaning in the world, how man understands life, how the she or he is shaped by building, by '...letting ourselves and the world be, and this letting-be includes the ways we build, see, understand, and think' characterizes a tradition of thinking in architecture which deals with human experience. Michael Marder, a plant ethicist extends this ethics of care for the environment, from a letting-be of the natural environment to a learning from and even becoming them (plants). He argues that if plants have a social life, if they communicate with one another, and if with exquisite sensitiveness they can feel pain, must we then have a greater ethic towards them. If they have feelings, should we eat them? Their model of society and community may even be more appropriate for us, he argues. 


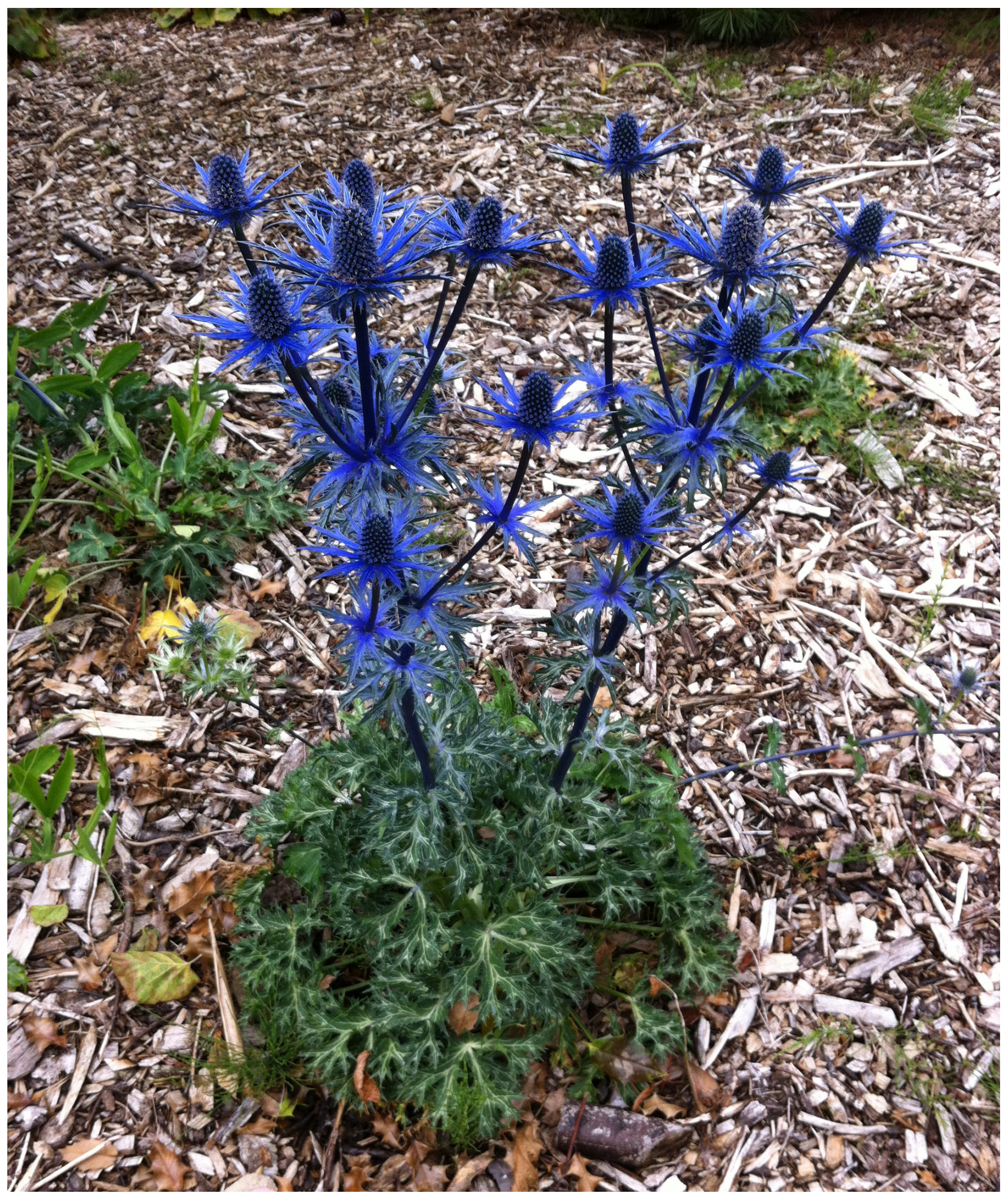

Figure 4 Posing Questions About Vegetal Being 
Marder describes a revolutionary an-architecture of exteriority shaped by his plant ethics, an '...abiding in absolute exteriority [...] quintessentially anarchitectural.' He argues: 'Vegetal anarchitectures demand something else altogether. They dare to dream of another dwelling, one that would put us in touch with the elements without simply leaving us at their mercy.'

Marder has also co-authored a book entitled Through Vegetal Being with a pivotal feminist philosopher Luce Irigaray, renown for her radical criticism of the philosophical tradition, because, she argues, of its lack of ethic to the female. It is in this dialogue that a confrontation between contemporary social and vegetal ethics becomes evident. Irigaray challenges Marder's vegetal ethic, as lacking human developmental concern. According to Irigaray, it undervalues what it means to be human. While Marder argues that we need a different attitude to dwelling (as does Irigaray) and we need to embrace vegetal anarchy in our soujourn in the world: 'To disperse the sovereign meanings of building, edifying, housing, and sheltering, so that their anarchitectural overtones would proliferate in the manner of adventitious roots and shoots.' What it means to be human is, what it means for the human to find meaning, cannot however so easily be satisfied by a love of plants, from Irigaray's feminist perspective. Humans are social beings, and desire other human beings, she argues. They are curious and have feelings for other human beings and learn from other humans, and human relationships are illdeveloped in our contemporary cultures. Especially to those who can feel other. Some of the most ill-considered ethics we have are those to humans who are radically different to ourselves. To construct an ethical dwelling for Irigaray requires not a learning from plants but from others, and moreover radical others; a social ethic that opens up the limitations of our cultures, and its apparent social certainties.

\section{AN ENVIRONMENT FOR A NEW HUMAN}

Irigaray's philosophy places an ethic towards the other, as the most radical and unthought of all ethics. This was the subject of one of her first significant publications: Speculum. Of the Other Woman. This is not without controversy. Rather than seeking inspiration from the vegetal world, she argues that we need to look to ourselves and our own human desires and go beyond cultural limitations in how we understand the human other. This suggests philia not for the vegetal world, but love for the other who is human, a love that cultivates and nurtures a radically other human, and his or her development. It is not only an ethic, it is she suggests human duty; revisioning both anarchitecture (as Marder describes) and architecture, towards a radical coexistence. This means new ways of living and being, and as she argues in one of her most recent books the birth of a new human. A concern for who we are as human beings is not an approach to sustainable architecture as a technical fix, but an aspiration to design that communicate our desire for human development.
Such radical philosophies have an important place in the dialogue of sustainable building in that they challenge and unsettle preconceptions. Irigaray, moreover, has written on a social ethic in architecture albeit dismissed by theorists perhaps too sure of their convictions. There are no simple answers to whether human aspirations to create sustainable architecture should adopt more social or environmental ethics, or where such priority can be placed. As Guy states, what differs in approaches to sustainable architecture is the degree of certainty to that which is deemed the problem. Nevertheless, radical philosophies describe some sophiciated criticisms of this dilemma. Our relationship with nature, with the weather, with the other, with the stranger who arrives at the dwelling, these are the fundamentals of concerns for architects and not just those within the environmental tradition. Evolving visions of what nature is, and what our relationship is with nature will forever guide architects, but if we close our horizon to lies outside our traditions of thinking and feeling we will remain limited in our approach to the problem of sustainable design, all too certain in our convictions.

\section{ENDNOTES}

1 McKibben 2011, Eaarth: Making a Life on a Tough New Planet. Canada, Vintage Books, 61.

2 Guy, S, \& Farmer, G., 2001. 'Reinterpreting sustainable architecture: the place of technology'. Journal of Architectural Education, 54 (3), 143

3 Idem., 141.

4 Idem., 140.

5 Idem., 141

6 James, C., 2017 'Interspatiality. Space and the Environment - A Conceptual Approach'. The Sustainable City IX, 2, 1026..

7 Guy, S., 2010. 'Pragmatic Ecologies: Situating Sustainable Building', Architectural Science Review, 53 (1), 21.

8 Ehrenfeld, J., 2008. Sustainability by Design: A Subversive Strategy for Transforming our Consumer Culture. New Haven, Yale University Press, 97.

9 Ehrenfeld, J. R., and Hoffman, A. J., 2013. Flourishing: A Frank Conversation About Sustainability. London, Routledge, Greenleaf Publishing.

10 Orr, D.W, 2007, Architecture, Ecological Design, and Human Ecology, in K. Tanzer and R. Longoria (eds), The Green Braid: Towards an Architecture of Ecology, Economy, and Equity. (London, Routledge, 15-33); Orr, D. W., 2009. Down to the Wire: Confronting Climate Collapse. (Oxford, Oxford University Press; Orr, D. W., 2010). 'Two View of Our Planet's Future'. Nature, 464, 29 April.

11 Orr, D. W., 2006. 'Place and Pedagogy'. In M.K. Stone and Z. Barlow (eds.), Ecological Literacy: Educating our Children for a Sustainable World. San Francisco: Sierra Club Books; Orr, D. W., 1992. Ecological Literacy: Education and the Transition to a Postmodern World. (Albany: State University of New York Press).

12 Walker, S., 2011. The Spirit of Design: Objects, Environment and Meaning London, Earthscan publications; Walker, S., 2012. Sustainable by design: Explorations in theory and practice. (London, Routledge; Walker, S., 2014). Designing Sustainability: Making Radical Changes in a Material World. London, Routledge.

13 Orr, 2007

14 Walker 2013, 90

15 Jackson, T., 2009. Prosperity Without Growth: Economics for a Finite Planet London, Earthscan publications limited; Jackson, T., 2016. Prosperity Without Growth: Foundations for the Economy of Tomorrow. Abingdon, Oxford, Taylor \& Francis

16 Jackson, T., et al., 2016. 'Understanding sustainable prosperity - toward a transdisciplinary research agenda'. CUSP Working Paper No 1. Guildford: University of Surrey. Online at: www.cusp.ac.uk/publications, 3 ..

17 Idem, 6 .

18 Baker, S., 2006. Sustainable Development. London, Routledge, 28. 
19 Ibid.

20 Brundtland, G. H., 1987. 'Our common future'. United Nations World Commission on Environment and Development (WCED), Rio de Janeiro.

21 Walker, S., 2013. Design and Spirituality: Material Culture for a Wisdom Economy. Design Issues, 29(3), 92.

22 Baker 2006, 34.

23 Hawken, P., 2017. Drawdown. The Most Comprehensive Plan Ever Proposed to Reverse Global Warming. London, Penguin Books, xi.

24 Idem, 13.

25 Seamon, D., 1998. 'Concretizing Heidegger's Notion of Dwelling: The Contributions of Thomas Thiis-Evensen and Christopher Alexander'. International Journal of Architectural Theory, 3(2), 189-202.

26 Hulme, M., 2016. Weathered: Cultures of Climate. London, Sage.

27 Hulme, M., 2015. 'Climate. Living Lexicon for the Environmental Humanities'. Environmental Humanities, 6, 175.

28 Ehrenfeld 2013, 5-4.

29 Idem, 89

30 Ibid.

31 Guy and Farmer 2001, 145..

32 Fielding, N. G., 2016 'Challenging Others' Challenges Critical Qualitative Inquiry and the Production of Knowledge'. Qualitative Inquiry, 32 (1), 25.

33 Beck, U. \& Sznaider, N., 2006. 'Unpacking Cosmopolitanism for the Social Sciences: A Research Agenda'. The British Journal of Sociology, 57 (1), 22.

34 Pink, S., Tutt, D., Dainty, A and Gibb, A. 2010 'Ethnographic methodologies for construction research: knowing, practice and interventions'. Building Research and Information, 38 (6), 647-659.

35 Hawkes, D., 1996. The Environmental Tradition, studies in the architecture of the environment, London, E\&FN Spon; Hill, J., 2012. Weather Architecture. London and New York, Routledge.

36 Seamon 1998, 189.

37 Marder, M., 2012. 'If Peas can talk should we eat them?' The Opinion Pages. New York Times, 28 April.

38 Marder, M., 2016. 'Vegetal Anarchitectures' The Philosophers Plant. Los Angeles Review of Books Channel. http://philosoplant.lareviewofbooks. org/?p=164

39 Idem.

40 Irigaray, L., and Marder, M., 2015 Through Vegetal Being. New York, Columbia Press.

41 Marder 2016

42 Irigaray, L, 2017. To Be Born. London, Palgrave.

43 Rawes, P., 2007. Irigaray for Architects. London, Routledge. Growth: Foundations for the Economy of Tomorrow. Abingdon, Oxford, Taylor \& Francis. 